\title{
Histochemical Expression of Mast Cell Chymase in Chronic Periodontitis and Cyclosporine-Induced Gingival Overgrowth
}

\author{
Tamilselvan Subramani, ${ }^{1,2}$ Kamatchiammal Senthilkumar, ${ }^{3}$ and Soundararajan Periasamy ${ }^{4}$ \\ ${ }^{1}$ Department of Cell and Molecular Biology, Faculty of Biotechnology and Biomolecular Sciences, Universiti Putra Malaysia, \\ 43400 Serdang, Selangor, Malaysia \\ ${ }^{2}$ Department of Periodontics, Faculty of Dental Science, Sri Ramachandra University, Chennai 600116, India \\ ${ }^{3}$ Virology Division, National Environmental Engineering Research Institute, Chennai 600113, India \\ ${ }^{4}$ Department of Nephrology, Faculty of Medicine, Sri Ramachandra University, Chennai 600116, India \\ Correspondence should be addressed to Tamilselvan Subramani; drstamilselvan@gmail.com
}

Received 18 February 2013; Revised 27 March 2013; Accepted 28 March 2013

Academic Editor: Francesco Cappello

Copyright (C) 2013 Tamilselvan Subramani et al. This is an open access article distributed under the Creative Commons Attribution License, which permits unrestricted use, distribution, and reproduction in any medium, provided the original work is properly cited.

\begin{abstract}
Mast cell (MC) mediators play a vital role in fibrosis. The purpose of this study was to investigate the MCs and their enzyme chymase in gingival tissues showing drug-induced gingival overgrowth (DIGO) and also to evaluate the correlation of MC counting and expression with the chronic periodontitis. In this study, 30 samples, including cyclosporine-induced gingival overgrowth, chronic periodontitis (10 for each), and ten normal gingival tissues, were collected. We analyzed the histochemical expression of MC chymase in all the collected tissues. In addition, the number of MCs was counted for each deparaffinized section stained with toluidine blue. Furthermore, total RNA was extracted from tissue samples, and RT-PCR was performed for MC chymase. The numbers of MCs were found to be increased in relative lesions compared to normal gingival tissues $(P<0.05)$. Moreover, chymasecontaining MCs in DIGO tissues showed striking differences from those of control subjects and chronic periodontitis $(P<0.01)$. The RT-PCR analysis further revealed that MC chymase mRNA increased significantly in DIGO tissues. In conclusion, although the MCs were less numerous in numbers, the cells exhibited significant expression of chymase enzyme suggesting the involvement of MCs in DIGO.
\end{abstract}

\section{Introduction}

Mast cells (MCs) are present in almost all human tissues and have been implicated in the pathogenesis of a variety of chronic inflammatory diseases. MCs contain various kinds of biochemical mediators: enzymes, such as histamine, heparin, tryptase, and chymase, and cytokines, including interleukin(IL-) 4, IL-5, IL-6, and IL-8 in cytoplasmic granules $[1,2]$. The release of these substances from MCs in inflammatory lesions is thought to play an important role in acceleration of the inflammatory process, angiogenesis, and fibrosis [2, 3]. According to their protease content, human MCs have been divided into two phenotypes: tryptase-positive and chymasepositive phenotypes, and both phenotypes are present in almost all human tissues.

Drug-induced gingival overgrowth (DIGO) is an unwanted outcome of systemic medication and is limited to gingiva. Drugs associated with gingival enlargement are anticonvulsants (phenytoin), calcium channel blockers (nifedipine), and immunosuppressant such as cyclosporine-A $[4,5]$. Although the pharmacological effects of these drugs are different and directed toward various primary target tissues, all of them seem to act similarly on a secondary target tissue, that is, the gingiva, causing almost similar clinical and histopathological findings. Although many theories are prevalent about DIGO, most of the studies have confirmed the significance of presence of inflammation as prerequisite for the overgrowth to occur [6-9]. The inflammatory response determines the destructive process of the disease and stimulates the resident epithelial cells, endothelial cells, and fibroblasts responding to proinflammatory mediators and participating in this tissue destruction [2]. Recent studies have focused on the role of MC chymase in the pathogenesis 
of DIGO. Experimental studies have demonstrated that MC chymase is associated with the development of bleomycininduced murine pulmonary fibrosis [10], heart failure [11], and mesenteric vascular collagen deposition in rat diabetic kidneys [12]. These findings suggest that MC chymase plays an important role in the development of fibrosis. Because inflammation is a prerequisite for DIGO, this study was designed to assess the expression of mast cell and its enzyme chymase in CsA-induced gingival overgrowth tissues.

\section{Materials and Methods}

2.1. Gingival Tissue Samples. CsA-medicated DIGO tissue samples were collected during gingivectomies from lower anterior and upper posterior of 10 patients ( 5 males and 5 females) aged 40-60 years. Gingival tissues were obtained at the time of resective surgery from marginal papillary and attached gingiva of 10 chronic periodontitis patients aged 22-60 years (5 males and 5 females). Ten control samples (5 males and 5 females) were also obtained from upper and lower premolar regions of healthy individuals, aged 13-17 years, who have undergone orthodontic treatment. Patients who are under medication for minimum period of one year to CsA, who developed clinically significant gingival overgrowth within 6 months of intake of the drug, were included in the study. The chronic periodontitis expressed clinical signs of inflammation and was taken from sites with a probing depth greater than $6 \mathrm{~mm}$ with evidence of bleeding on probing. The control subjects were systemically and periodontally healthy without gingival inflammation and showed no evidence of bleeding on probing with a probing depth less than $4 \mathrm{~mm}$. Gingival tissues which would normally be discarded at the time of periodontal surgery were retained if they meet the selection criteria. All the patients and healthy subjects were nonsmokers from enquiry on personal history. People who were medically compromised, who had antibiotic intake within 6 months, and who had undergone any periodontal therapy within 6 months were excluded from the study. All the procedures were performed with appropriate written informed consent from all subjects and were approved by the Institutional Ethical Committee and Review Board of Sri Ramachandra University, Chennai, India.

2.2. Toluidine Blue Staining. The gingival tissues were cut into $4 \mathrm{~mm}$ thin sections, dried and deparaffinized to distilled water, then embedded in toluidine blue (Sigma, New Delhi, India) working solution for 3 minutes, later washed in distilled water (3 times), dehydrated quickly through $95 \%$ and 2 times of $100 \%$ alcohol, and finally were cleared 2 times in xylene. The positive-stained mast cells were counted in 10 consecutive nonoverlapping microscopic fields at a magnification of 400, and the average number of mast cells per high power field was calculated. The number of mast cells was counted by a single examiner in and compared between the cases and control groups.
2.3. Histochemical Staining for Mast Cell Chymase. For histochemical studies, $5 \mu \mathrm{m}$ thin sections were cut on polyL-lysine-coated slides. Enzymatically active chymase was stained enzyme histochemically using an incubation mixture containing $1 \mathrm{~mm}$ Suc-Val-Pro-Phe-MNA as the substrate, $0.5 \mathrm{mg} / \mathrm{mL}$ fast black K salt (Sigma, New Delhi, India) as the chromogen, $1 \mathrm{mg} / \mathrm{mL}$ aprotinin as the inhibitor to inhibit possible other chymotryptic proteinases, and $100 \mathrm{~mm}$ Tris$\mathrm{HCl}$ buffer, $\mathrm{pH}$ 7.5. The mast cells with positive chymase were counted and compared between groups.

2.4. Isolation of Total RNA and Reverse TranscriptionPolymerase Chain Reaction (RT-PCR). The total RNA was isolated from the gingival tissues by single-step, acid guanidium thiocyanate phenol chloroform extraction method [13]. The total RNA was transcribed to cDNA using First Strand cDNA synthesis Kit (Qbiogene, Chandigarh, India) for reverse transcription polymerase chain reaction (RT-PCR) according to manufacturer instructions. The primers were designed from the known sequences as chymase $5^{\prime}$-CCACTCCCCCTGTATCTTGC-3' (sense) and $5^{\prime}$-CAGGGGTGCGTTTAGGGATT- $3^{\prime}$ (antisense); $\beta$ actin $5^{\prime}$-AAGGATTCCTATGTGCCG-3' (sense) and $5^{\prime}$ CATCTCTTGCTCGAAGTC- $3^{\prime}$. Primers were from Biocorporals, Chennai, India, and other laboratory chemicals were from Merck, Chennai, India. The amplification profile was as follows: denaturing at $94^{\circ} \mathrm{C}$ for $1 \mathrm{~min}$; annealing at optimal temperature $\left(60^{\circ} \mathrm{C}\right.$ for chymase and $53^{\circ} \mathrm{C}$ for $\beta$-actin) for $2 \mathrm{~min}$; extension at $72^{\circ} \mathrm{C}$ for $2 \mathrm{~min}$. The cDNA was amplified in Perkins Elmer PCR analyzer for 36 cycles followed by a step of $10 \mathrm{~min}$ at $72^{\circ} \mathrm{C}$ to extend the partially amplified products. These cycling conditions were established empirically to give linear increase in product intensity proportional to the amount of template. The PCR products were electrophoresed using Bang-Genei electrophoresis apparatus on 1.2\% agarose gel (Hi Media, Chennai, India) and visualized by ethidium bromide (Sigma, New Delhi, India) staining. The gels were photographed, and their image data were analyzed by BioRad image analyzer (1D analysis). The relative amount gene expressions was calculated as the ratio of the individual chymase to the intensity of $\beta$-actin gene products as the control. The relative expression of chymase gene control, chronic periodontitis, and DIGO tissues were compared.

2.5. Statistical Methods. The data were analyzed statistically using nonparametric tests, including Kruskal-Wallis and Mann-Whitney tests, and $P$ value $<0.05$ was considered as significant. The difference in the levels of expression of the chymase gene between control group, inflammation, and DIGO groups was analyzed by the Fischer exact test. Results are presented as mean \pm SEM. $P$ value $<0.05$ was considered statistically significant.

\section{Results and Discussion}

In microscopic sections stained with toluidine blue, mast cells were seen as purple and granular mononuclear cells (positive metachromatic reaction; Figures 1(a) and 1(b)). 


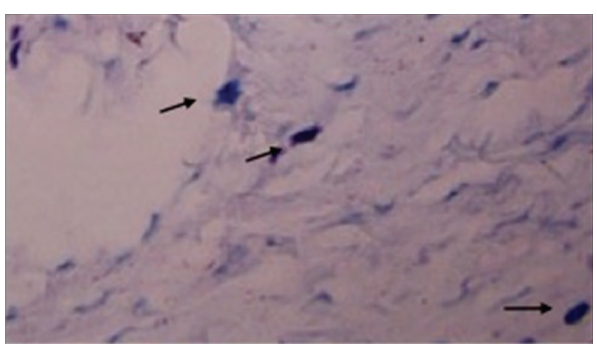

(a)

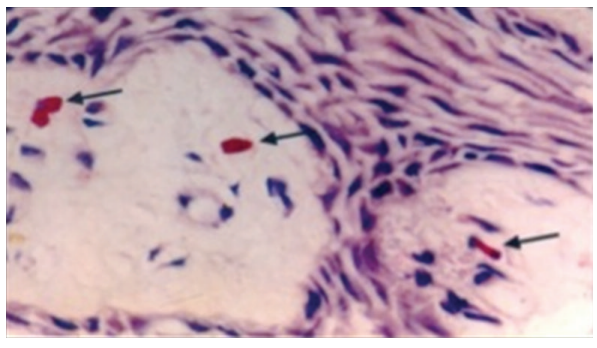

(c)

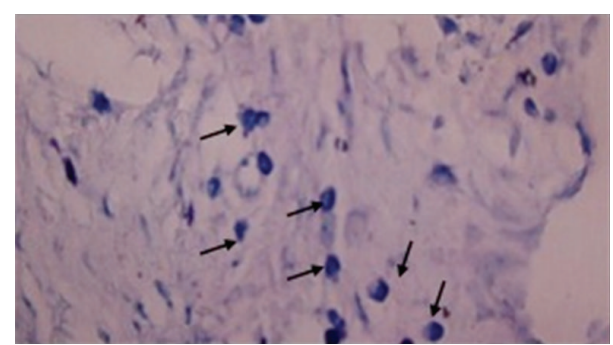

(b)

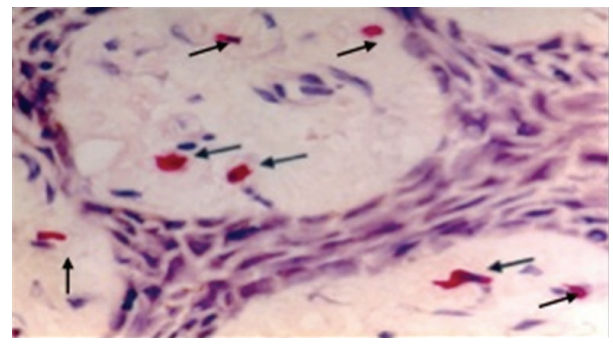

(d)

Figure 1: The mast cell and mast cell chymase expressions were studied in the gingival tissues. The cells with metachromatic reaction (arrows) in connective tissue of (a) control; (b) DIGO tissues (toluidine blue, $\times 400$ ). Enzyme histochemical expression of mast cell chymase in (c) control; (d) DIGO tissues $(\times 400)$. Chymase positive mast cells are numerous in the DIGO tissues.

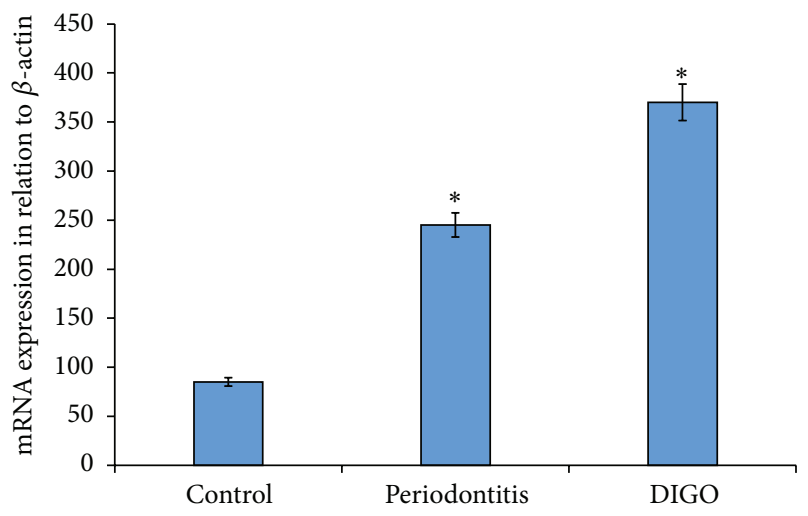

FIGURE 2: mRNA expression of mast cell chymase in gingival samples obtained from patients with DIGO, patients with periodontitis, and normal healthy subjects (control). Total RNA was isolated, and RT-PCR was performed using gene-specific primers. $\beta$-Actin was used as the internal control for PCR. Each bar gives the mean \pm SE of ten cDNA samples. ${ }^{*} P<0.001$ versus control.

The mast cells were detected in all cases of DIGO, chronic periodontitis, and normal gingival tissues. The mean total number of mast cells was 87.6 (range: 46-121) in DIGO, 57.7 (range: 14-108) in chronic periodontitis, and 24 (range: 1632 ) in normal gingival tissues. The nonparametric KruskalWallis test showed a significant difference between groups $(P=0.001)$. The enzyme histochemical analysis of mast cell chymase showed a mean total number of chymase positive mast cells of 57.9 (range: 10-104) in DIGO (Figure 1(b)), of 39.4 (range: 11-81) in chronic periodontitis, and of 19.7 (range: 7-59) in normal gingival specimens (Figures 1(c) and 1(d)).
The nonparametric Kruskal-Wallis test revealed a significant difference between groups $(P=0.019)$. Analysis of the percentage of chymase positive mast cells showed a larger mean number in DIGO than in chronic periodontitis and normal gingival tissue specimens $(P<0.001)$. To verify that the chymase expression is augmented in DIGO tissues, we carried out the RT-PCR analysis for mast cell chymase. The amount of chymase mRNA in DIGO tissues was significantly increased by 3.6 folds compared to healthy gingival tissues (Figure 2). Our study confirms that mast cell is expressed by the great majority in DIGO tissues obtained from CsAmedicated kidney transplanted patients, whereas it was poorly expressed in healthy tissues. Moreover, remarkable percentages of chymase positive mast cells were found in the DIGO tissues. These findings from histochemical assays demonstrated significant correlations between the DIGO and the number of infiltrating chymase-positive mast cells, suggesting that mast cells play an important role in the process of DIGO. These findings extended other studies that focused on the involvement of mast cells in DIGO, to determine the general role of mast cells in the development of gingival fibrosis not only in CsA but also in nifedipine and phenytoin-induced gingival overgrowth tissues $[14,15]$. Of note, chymase-positive mast cells were mainly detected in significant number in CsA-induced fibrotic lesions of gingiva, rather than nifedipine- and phenytoin-induced fibroses. All the evidences strongly suggested that mast cells are unique contributors to the development of CsA-induced gingival overgrowth. Activation of mast cells can usually be induced by multiple mechanisms, including IgE and complementmediated pathways. Stem cell factor (SCF) has also been identified as a differentiation, chemoattraction, and activation factor for mast cells in human subjects $[16,17]$. 
Another study reported that SCF was constitutively produced by pulmonary fibroblasts and could be induced by tumor necrosis factor- (TNF-) $\alpha$, which is contained in mast cells [18]. We have shown that expression of TNF- $\alpha$ was significantly elevated in DIGO tissues compared to chronic periodontitis [19]. Therefore, it was suggested that activated gingival fibroblasts may produce SCF during inflammation, to attract mast cells to injured sites.

MCs may have some role in connective tissue turnover [20], and they accelerate the migration and proliferation of fibroblasts in vitro [21]. In fact, MCs can affect the fibroblast's functional behavior and, consequently, the fibrosis process by releasing preformed mediators, such as histamine, proteoglycans, proteolytic enzymes, newly formed mediators, and fibrogenic cytokines like platelet-derived growth factor and basic fibroblast growth factor $[20,22]$. The secreted enzyme chymase from MCs has been demonstrated to induce fibroblast proliferation and collagen type 1 synthesis [23]. The culture of MCs and fibroblasts results in fibroblast proliferation, which is modulated by direct cell-cell contact [24]. Our previous study demonstrated the existence of intrinsic gingival renin angiotensin system (RAS) components as well as augmented angiotensin II (Ang II) expression in gingival fibroblast cells treated with CsA [25]. The question posed by the current investigation is that how the local RAS contributes to the remodeling in DIGO. The results of the current investigation suggest that localized increases of Ang II in DIGO tissues appear to be due to an increased mast cell density and chymase-mediated Ang II production compared to control. Although the development of fibrosis has been directly attributed to increased Ang II, a study by Nurmenniemi et al. [14] supported our finding that mast cells are involved in gingival fibrosis. This was also demonstrated in a study by de Almeida et al. [26] in which they found that incubation of cardiac fibroblasts with mast cell supernatant produced an inhibition of fibroblast migration, altered integrin-receptor expression, and induction of collagen and MMP synthesis.

\section{Conclusion}

Conclusively, based on the aforementioned findings, MCs may play some roles in the formation of CsA-induced gingival overgrowth, and these findings suggest that early prevention of mast cell degranulation and/or inhibition of chymase may serve as potential pharmacologic interventions to prevent subsequent gingival remodeling contributing to the development of DIGO.

\section{Conflict of Interests}

The authors declare that they have no conflict of interests.

\section{References}

[1] L. J. Walsh, "Mast cells and oral inflammation," Critical Reviews in Oral Biology and Medicine, vol. 14, no. 3, pp. 188-198, 2003.
[2] G. Nilsson, J. J. Costa, and D. D. Metcalfe, "Mast cells and Basophils," in Inflammation: Basic Principles and Clinical Correlates, J. I. Gallin and R. Snyderman, Eds., pp. 97-117, Lippincott Williams \& Wilkins, Philadelphia, Pa, USA, 3rd edition, 1999.

[3] S. Tamilselvan, R. Vidhya, S. K. Yeap, and N. B. Alitheen, "Influence of mast cell in drug induced gingival overgrowth," Mediators of Inflammation, vol. 2013, Article ID 275172, 8 pages, 2013.

[4] K. Masatoshi, K. Junichi, S. Yasuo, and N. Toshihiko, "Druginduced gingival overgrowth-a review," Biological and Pharmaceutical Bulletin, vol. 28, no. 10, pp. 1817-1821, 2005.

[5] S. Nishikawa, T. Nagata, I. Morisaki, T. Oka, and H. Ishida, "Pathogenesis of drug-induced gingival overgrowth. A review of studies in the rat model," Journal of Periodontology, vol. 67, no. 5, pp. 463-471, 1996.

[6] T. M. Hassell and A. F. Hefti, "Drug-induced gingival overgrowth: old problem, new problem," Critical Reviews in Oral Biology and Medicine, vol. 2, no. 1, pp. 103-137, 1991.

[7] R. A. Seymour, J. S. Ellis, and J. M. Thomason, "Risk factors for drug-induced gingival overgrowth," Journal of Clinical Periodontology, vol. 27, no. 4, pp. 217-223, 2000.

[8] E. Varga, M. A. Lennon, and L. H. Mair, "Pre-transplant gingival hyperplasia predicts severe cyclosporin-induced gingival overgrowth in renal transplant patients," Journal of Clinical Periodontology, vol. 25, no. 3, pp. 225-230, 1998.

[9] S. Tamilselvan, S. N. Raju, D. Loganathan, S. Kamatchiammal, G. Abraham, and R. Suresh, "Endothelin-1 and its receptors ET(A) and ET(B) in drug-induced gingival overgrowth," Journal of Periodontology, vol. 78, no. 2, pp. 290-295, 2007.

[10] K. K. Inenaga, M. Hara, K. Higuchi et al., "Gene expression of cardiac mast cell chymase and tryptase in a murine model of heart failure caused by viral myocarditis," Circulation Journal, vol. 67, no. 10, pp. 881-884, 2003.

[11] S. E. Jones, R. E. Gilbert, and D. J. Kelly, “Tranilast reduces mesenteric vascular collagen deposition and chymase-positive mast cells in experimental diabetes," Journal of Diabetes and its Complications, vol. 18, no. 5, pp. 309-315, 2004.

[12] T. Matsumoto, A. Wada, T. Tsutamoto, M. Ohnishi, T. Isono, and M. Kinoshita, "Chymase inhibition prevents cardiac fibrosis and improves diastolic dysfunction in the progression of heart failure," Circulation, vol. 107, no. 20, pp. 2555-2558, 2003.

[13] P. Chomczynski and N. Sacchi, "Single-step method of RNA isolation by acid guanidinium thiocyanate-phenol-chloroform extraction," Analytical Biochemistry, vol. 162, no. 1, pp. 156-159, 1987.

[14] P. K. Nurmenniemi, H. E. Pernu, and M. L. E. Knuuttila, "Mast cell subpopulations in gingival overgrowth induced by immunosuppressive and nifedipine medication," Journal of Periodontology, vol. 75, no. 7, pp. 933-938, 2004.

[15] M. Soory and A. Suchak, "The effects of human mast-cell products and of phenytoin on androgen $5 \alpha$-reductase expression in human gingival fibroblasts," Archives of Oral Biology, vol. 46, no. 9, pp. 847-855, 2001.

[16] J. Li, H. Lu, E. Plante, G. C. Meléndez, S. P. Levick, and J. S. Janicki, "Stem cell factor is responsible for the rapid response in mature mast cell density in the acutely stressed heart," Journal of Molecular and Cellular Cardiology, vol. 53, no. 4, pp. 469-474, 2012.

[17] Y. Amagai, A. Tanaka, A. Matsuda, K. Jung, K. Ohmori, and H. Matsuda, "Stem cell factor contributes to tumorigenesis of mast cells via an autocrine/paracrine mechanism," Journal of Leukocyte Biology, vol. 93, no. 2, pp. 245-250, 2013. 
[18] C. Hogaboam, S. L. Kunkel, R. M. Strieter et al., "Novel role of transmembrane SCF for mast cell activation and eotaxin production in mast cell-fibroblast interactions," Journal of Immunology, vol. 160, no. 12, pp. 6166-6171, 1998.

[19] S. Tamilselvan, D. Loganathan, S. Kamatchiammal, P. Soundararajan, A. Georgi, and R. Suresh, "Expression of TNF- $\alpha$ and RANTES in drug-induced human gingival overgrowth," Indian Journal of Pharmacology, vol. 42, no. 3, pp. 174-177, 2010.

[20] I. S. D. Roberts and P. E. C. Brenchley, "Mast cells: the forgotten cells of renal fibrosis," Journal of Clinical Pathology, vol. 53, no. 11, pp. 858-862, 2000.

[21] F. Levi-Schaffer and V. B. Weg, "Mast cells, eosinophils and fibrosis," Clinical and Experimental Allergy, Supplement, vol. 27, no. 1, pp. 64-70, 1997.

[22] C. Y. Li and J. Y. Baek, "Mastocytosis and fibrosis: role of cytokines," International Archives of Allergy and Immunology, vol. 127, no. 2, pp. 123-126, 2002.

[23] R. Reikki, I. T. Harvima, A. Jukkola, J. Ristile, and A. Oikarinen, "The production of collagen and the activity of mast-cell chymase increase in human skin after irradiation therapy," Experimental Dermatology, vol. 13, no. 6, pp. 364-371, 2004.

[24] A. Trautmann, G. Krohne, E. B. Bröcker, and C. E. Klein, "Human mast cells augment fibroblast proliferation by heterotypic cell- cell adhesion and action of IL-4," Journal of Immunology, vol. 160, no. 10, pp. 5053-5057, 1998.

[25] T. Subramani, K. Senthilkumar, S. Periasamy, and S. Rao, "Expression of angiotensin II and its receptors in cyclosporineinduced gingival overgrowth," Journal of Periodontal Research, 2012.

[26] A. de Almeida, D. Mustin, M. F. Forman, G. L. Brower, J. S. Janicki, and W. Carver, "Effects of mast cells on the behavior of isolated heart fibroblasts: modulation of collagen remodeling and gene expression," Journal of Cellular Physiology, vol. 191, no. 1, pp. 51-59, 2002. 

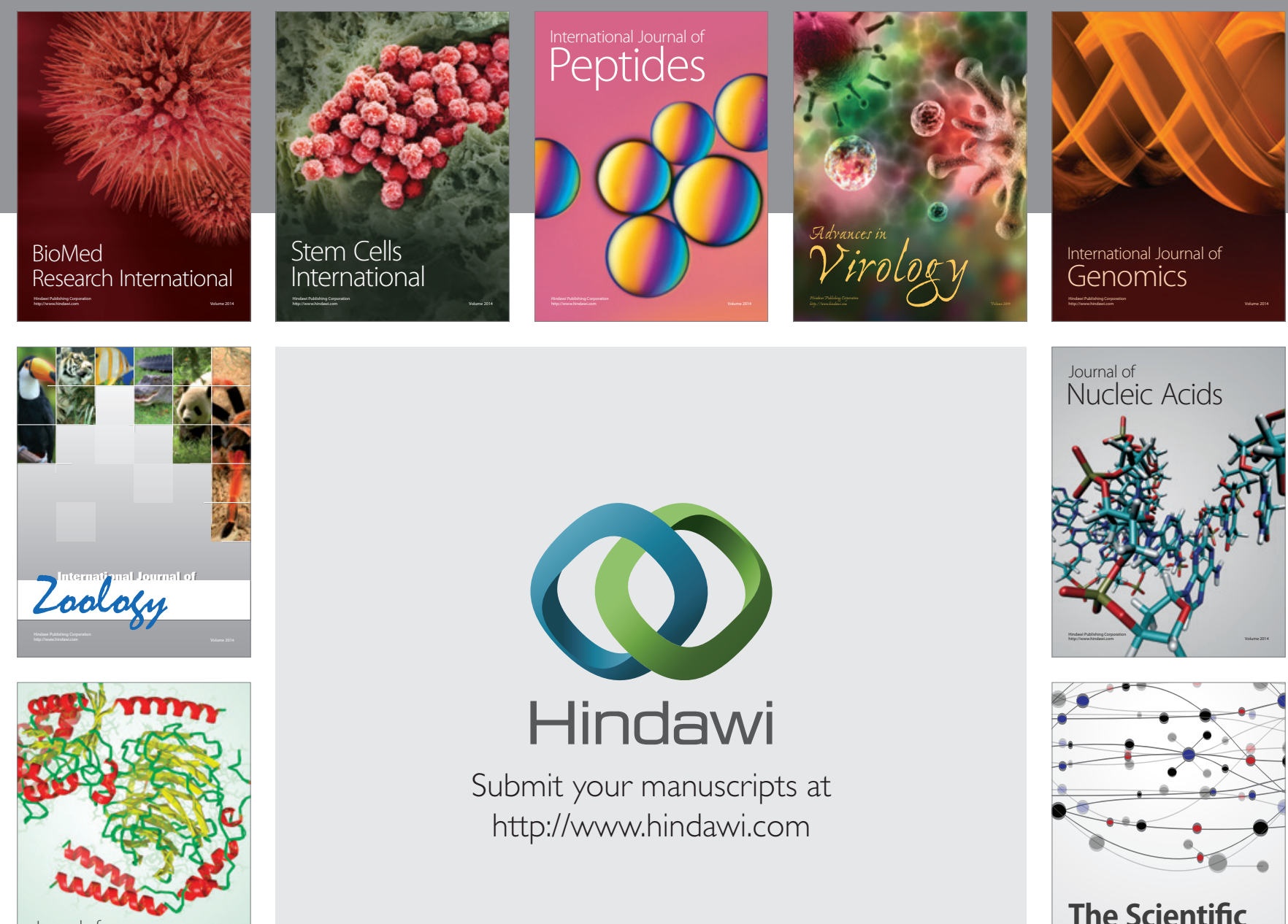

Submit your manuscripts at

http://www.hindawi.com

Journal of
Signal Transduction
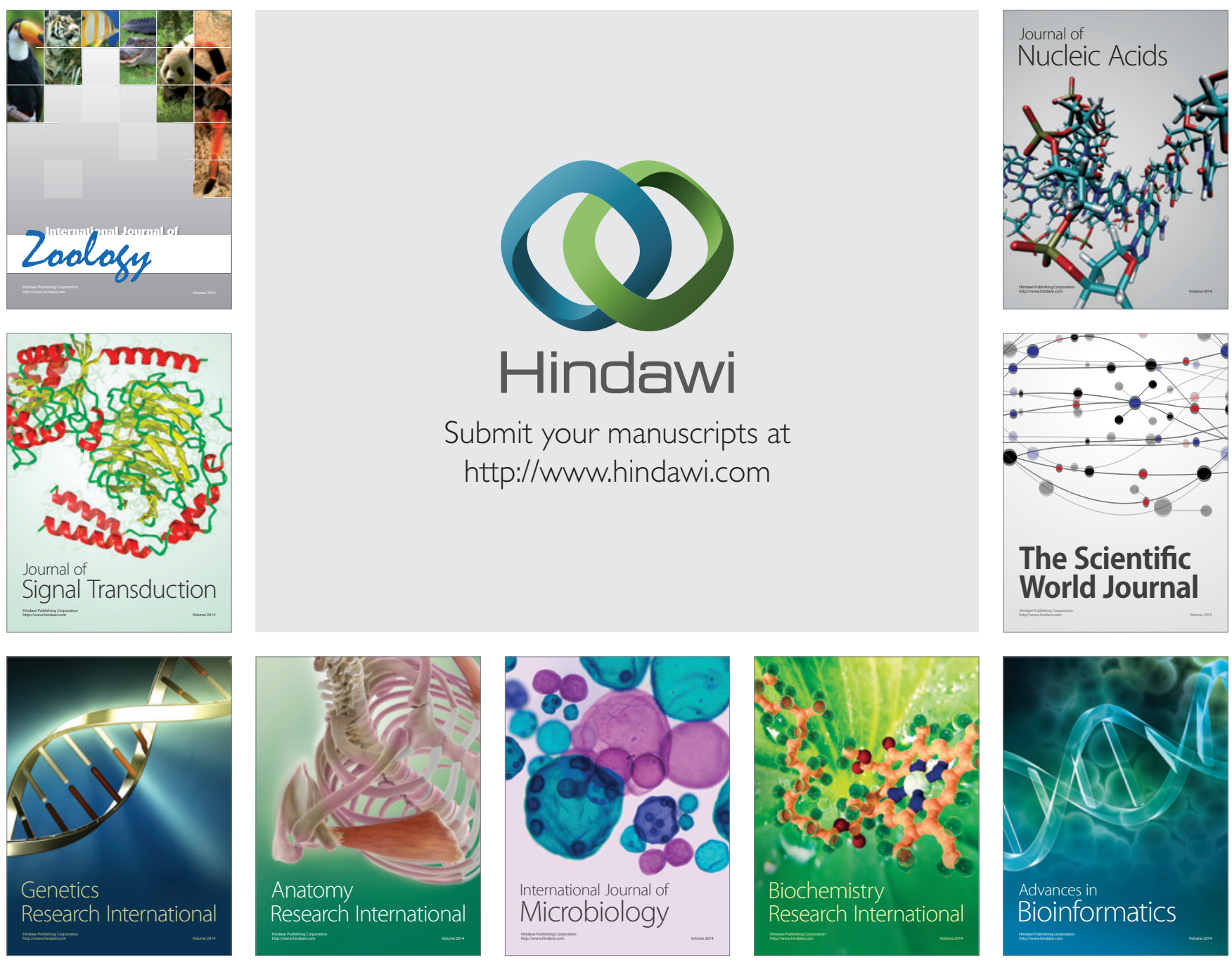

The Scientific World Journal
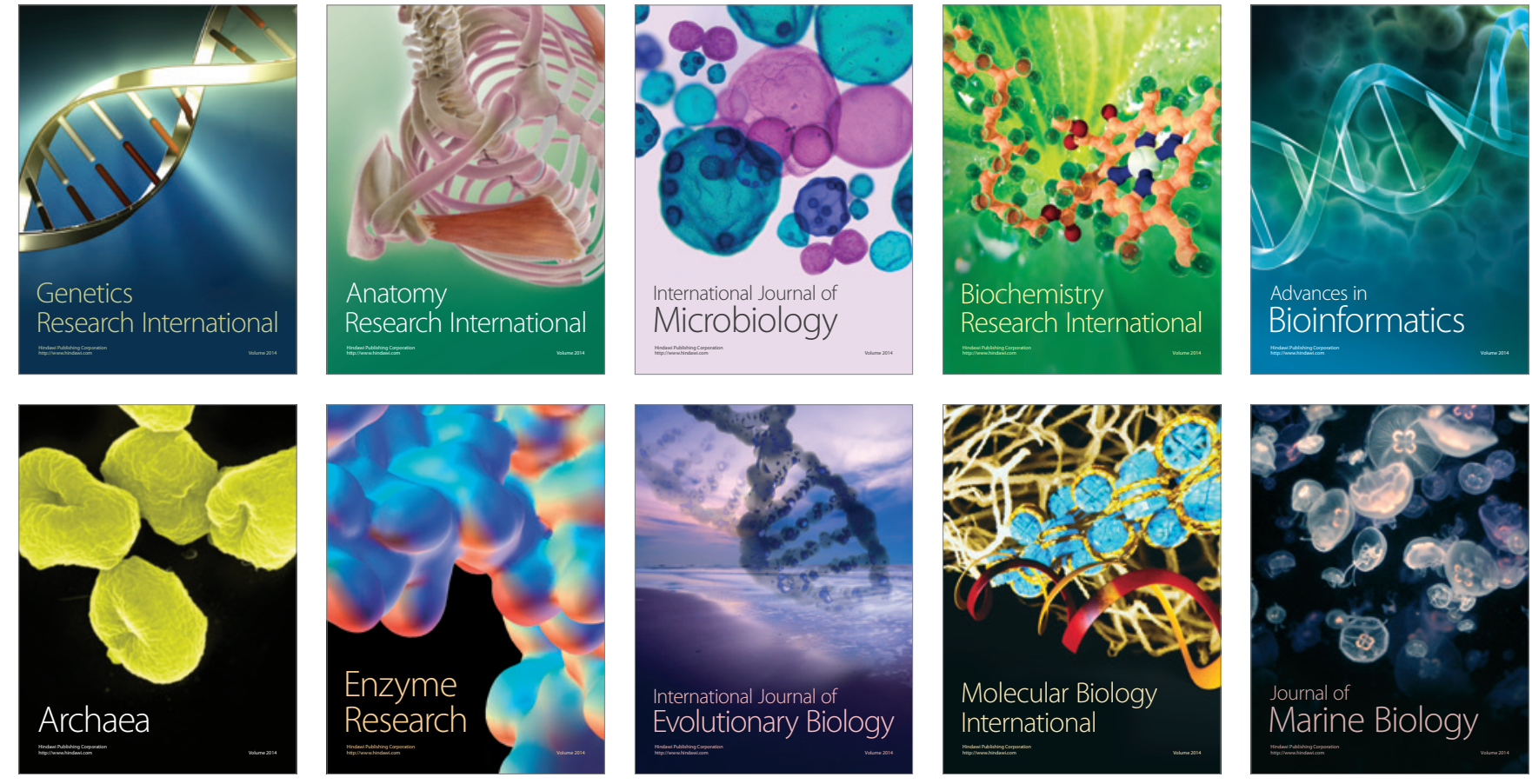